\title{
Detection of Phenotypic Variations and Biotypes of Staphylococcus aureus Obtained from Cattle Mastitic Milk
}

\author{
Pragya Nathiya*, Kumar Gaurav, Diwakar, Sandeep Kumar Sharma and A.K. Kataria
}

Department of Veterinary Microbiology and Biotechnology, RAJUVAS, Bikaner, Rajasthan-334001, India

*Corresponding author

\section{A B S T R A C T}

\section{Keywords}

Staphylococcus aureus,

Cattle, Phenotypic

variations, Biotypes,

Mastitis

Article Info

Accepted:

18 August 2018

Available Online:

10 September 2018
The present study was designed to find variations among Staphylococcus aureus on the basis of cultural and biochemical properties. From 59 samples of cattle clinical mastitic milk, 28 isolates were obtained and confirmed by species specific primers targeted against 23S rRNA with an amplicon of $1250 \mathrm{bp}$. The genotypically confirmed isolates were subjected to determine phenotypic variations among them. In our study total seven biotypes were detected with variations in pigment production, haemolysis pattern and coagulase production.

\section{Introduction}

Mastitis is one of the most important diseases affecting production in dairy industry worldwide and causes both direct and indirect losses to dairy farming (Petrovski et al., 2006). Staphylococcus aureus is the main causative agent responsible for clinical mastitis in cattle (Kateete et al., 2010). The organism exhibits variation on phenotypic properties and hence typing approaches are of significant importance to identify and understand the distribution of $S$. aureus strains among dairy herds. From the past few years, phenotypic methods such as antibiotic resistance typing, biotyping and phage typing are being used for typing of $S$. aureus isolates
(Wilson, 1987; Dallal et al., 2010). To biotype and characterize $S$. aureus, phenotypic methods like pigment production, coagulase production and haemolysis are easy, rapid and economical techniques for epidemiological investigations (Momtaz et al., 2011). The present study was designed to determine the biotypes on the basis of various pigment production, haemolysis, coagulase production and their ability to ferment mannitol.

\section{Materials and Methods}

\section{Collection of samples}

A total of 59 milk samples from cows irrespective of breed and age, with clinical 
mastitis were collected directly from teats in sampling tube, each about 5-10 $\mathrm{ml}$ in amount and then immediately taken to laboratory over ice for further processing on the same day. These animals belonged to different localities of Bikaner (Rajasthan).

\section{Isolation and identification of Staphylococcus aureus}

The organisms were isolated and identified as described by Cowan and Steel (1975) and Quinn et al., (1994). Briefly, milk sample was swabbed on nutrient agar medium and then incubated overnight at $37^{\circ} \mathrm{C}$. Next day different bacterial colonies were closely observed for their morphology, colour and consistency. Gram's staining, oxidase test and catalase test were used as primary identification tests and further the cultures were processed for confirmation by $23 \mathrm{~S}$ rRNA gene-based genotyping. For genotypic confirmation a set of species specific primers was used viz. forward - 5'-ACG GAG TTA CAA AGG ACG AC-3' and reverse - 5'-AGC TCA GCC TTA ACG AGT AC-3'(Straub et al., 1999).

\section{Biotyping of Staphylococcus aureus}

All genotypically confirmed isolates were further studied for cultural and biochemical properties. The isolates were cultured on mannitol salt agar and 5\% sheep blood agar and incubated for $24-48 \mathrm{~h}$ at $37^{\circ} \mathrm{C}$. Coagulase production test was carried out in tubes for production of free enzyme using human plasma according to Quinn et al., (1994). Biotypes were determined as per biotyping methodology described by Devriese (1984).

\section{Results and Discussion}

In the present study, out of 59 milk samples, 28 Staphylococcus aureus isolates were obtained with a recovery of $47.45 \%$ as confirmed by species specific PCR method targeted against $23 \mathrm{~S}$ rRNA with an amplicon of $1250 \mathrm{bp}$ (Fig. 1).

Of the 28 isolates, seven biotypes were detected on the basis of pigment production, mannitol fermentation, haemolysis on blood agar and coagulase production (Table 1), Staphylococcus aureus isolates of the biotype4 were found more prevalent $(42.85 \%)$ whereas biotype-1, 3 and 6 were found with minimum prevalence $(3.57 \%)$. All biotypes were mannitol fermenters (Fig. 2).

Out of seven biotypes, five biotypes produced golden yellow pigmentation (biotype-2, 3, 4, 5 and 6) while biotype-1 produced yellow pigmentation $(3.57 \%)$ and biotype- 7 produced white pigmentation (10.71\%). Only biotype-3 was negative coagulase production in tube coagulase test (Fig. 3).

In present investigation, out of the total biotypes, biotype-5 produced complete haemolysis, biotype-1 and 4, produced incomplete haemolysis (Fig. 4) and biotype-6 produced both (complete and partial) haemolysis whereas biotype-2, 3 and 7 did not produce any haemolysis. When biotypes $(1,4$ and 6) with incomplete and both haemolysis were incubated at $4^{0} \mathrm{C}$ to study hot-cold lysis, biotype-4 did not show hot-cold lysis whereas biotype-1 converted to complete haemolysis (hot-cold lysis) from incomplete haemolysis and biotype- 6 from both haemolysis (complete and partial) changed to complete haemolysis.

In the present investigation, a biotyping, was used to determine phenotypic variations among Staphylococcus aureus isolates which may be used for epidemiological surveillance. The prevalence rate $(47.45 \%)$ obtained in this study is in agreement with Seyoum et al., (2017) who reported $42.9 \%$ occurrence of $S$. aureus from clinical mastitis milk samples of cattle. 
Table.1 Cultural and biochemical variations among Staphylococcus aureus isolates via biotyping

\begin{tabular}{|c|c|c|c|c|c|c|c|}
\hline \multirow[t]{2}{*}{ S. $\mathbf{N}$. } & \multirow[t]{2}{*}{ Biotype } & \multirow[t]{2}{*}{ Isolate (n) } & \multirow{2}{*}{$\begin{array}{l}\text { Pigment } \\
\text { Production }\end{array}$} & \multirow{2}{*}{$\begin{array}{l}\text { Mannitol } \\
\text { Fermentation }\end{array}$} & \multicolumn{2}{|c|}{$5 \%$ Sheep Blood agar } & \multirow{2}{*}{$\begin{array}{l}\text { Coagulase } \\
\text { Production }\end{array}$} \\
\hline & & & & & $\begin{array}{l}\text { Haemolysis } \\
\text { Phenomena }\end{array}$ & $\begin{array}{l}\text { Hot Cold } \\
\text { lysis } \\
\text { Phenomena }\end{array}$ & \\
\hline 1. & $\begin{array}{l}1 \\
\text { Biotype1 }\end{array}$ & CM2 (1) & Yellow & Fermentative & Incomplete & $\begin{array}{l}\text { present } \\
\text { (Convert in } \\
\text { to Complete } \\
\text { haemolysis) }\end{array}$ & Positive \\
\hline 2. & Biotype 2 & $\begin{array}{l}\text { CM1, CM12, CM16, } \\
\text { CM20, CM26, CM28 } \\
\text { (6) }\end{array}$ & $\begin{array}{l}\text { Golden } \\
\text { yellow }\end{array}$ & Fermentative & Negative & Negative & Positive \\
\hline 3. & Biotype 3 & CM27 (1) & $\begin{array}{l}\text { Golden } \\
\text { yellow }\end{array}$ & Fermentative & Negative & Negative & Negative \\
\hline 4. & Biotype4 & $\begin{array}{l}\text { CM3, CM5, CM6, } \\
\text { CM9, CM11, CM13, } \\
\text { CM15, CM17, } \\
\text { CM19, CM21, } \\
\text { CM23, CM25 (12) }\end{array}$ & $\begin{array}{l}\text { Golden } \\
\text { yellow }\end{array}$ & Fermentative & Incomplete & Absent & Positive \\
\hline 5. & Biotype 5 & $\begin{array}{l}\text { CM4, CM8, CM14, } \\
\text { CM18 (4) }\end{array}$ & $\begin{array}{l}\text { Golden } \\
\text { yellow }\end{array}$ & Fermentative & Complete & Complete & Positive \\
\hline 6. & Biotype 6 & CM7 (1) & $\begin{array}{l}\text { Golden } \\
\text { yellow }\end{array}$ & Fermentative & Both & present & Positive \\
\hline 7. & Biotype7 & $\begin{array}{l}\text { CM10,CM22 CM24 } \\
\text { (3) }\end{array}$ & White & Fermentative & Negative & Negative & Positive \\
\hline
\end{tabular}

Fig.1 Agarose gel electrophoresis of amplicons of 23S rRNA ribotyping of S. aureus isolated from cattle with clinical mastitis

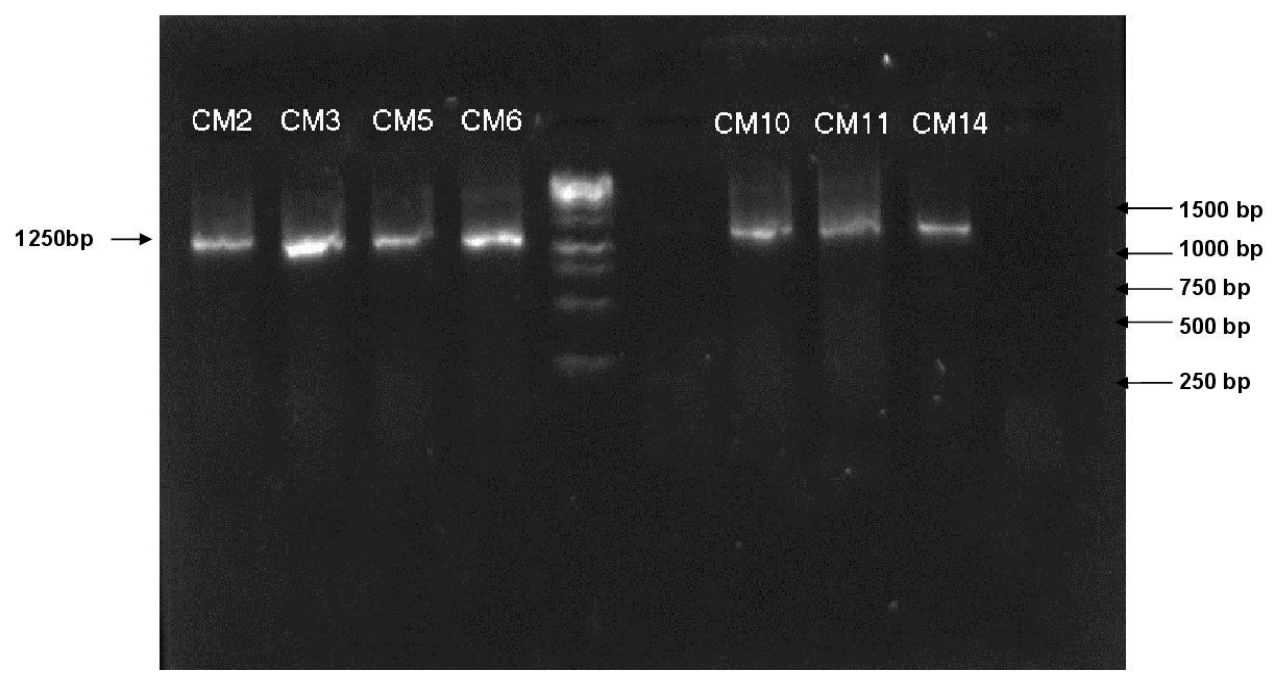


Fig.2 Mannitol fermentation by $S$. aureus isolated from cattle with clinical mastitis on Mannitol salt agar

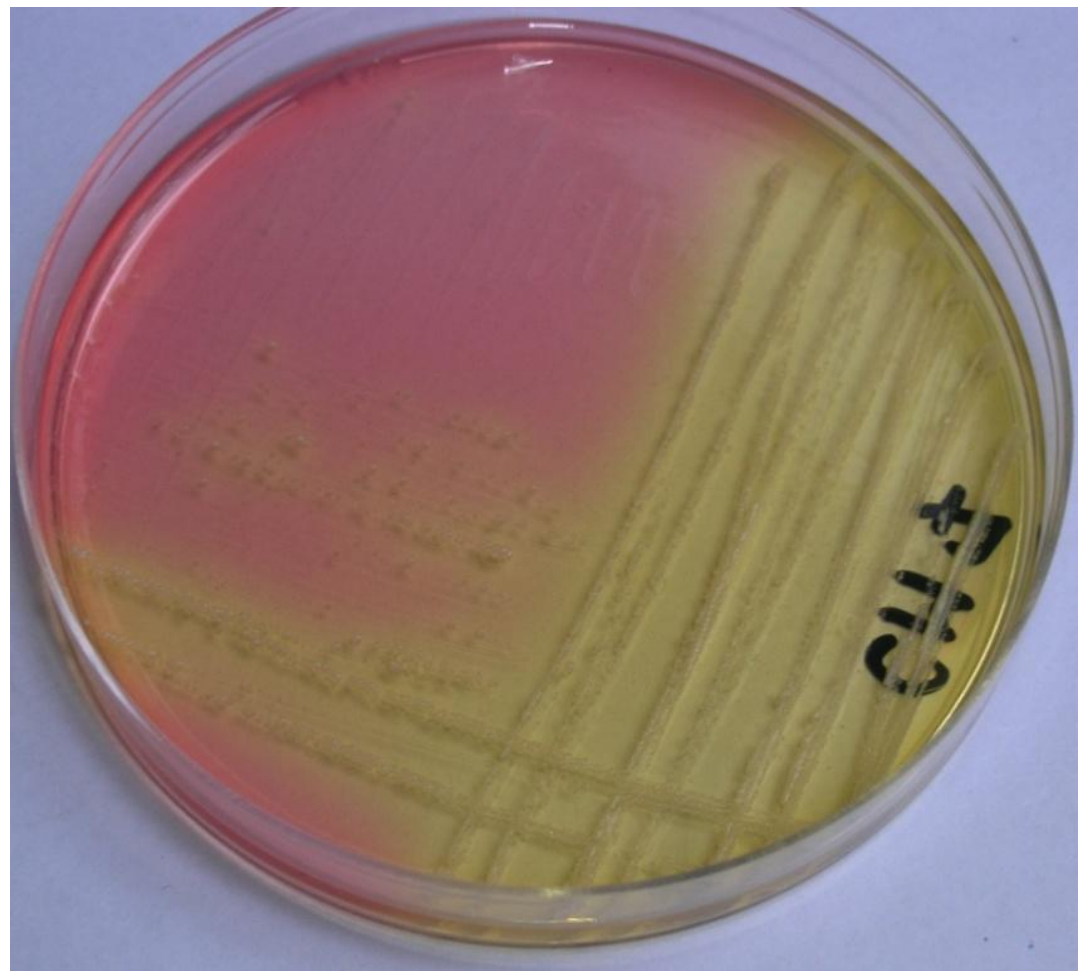

Fig.3 Tube coagulase test for S. aureus isolates obtained from cattle with clinical mastitis with human plasma

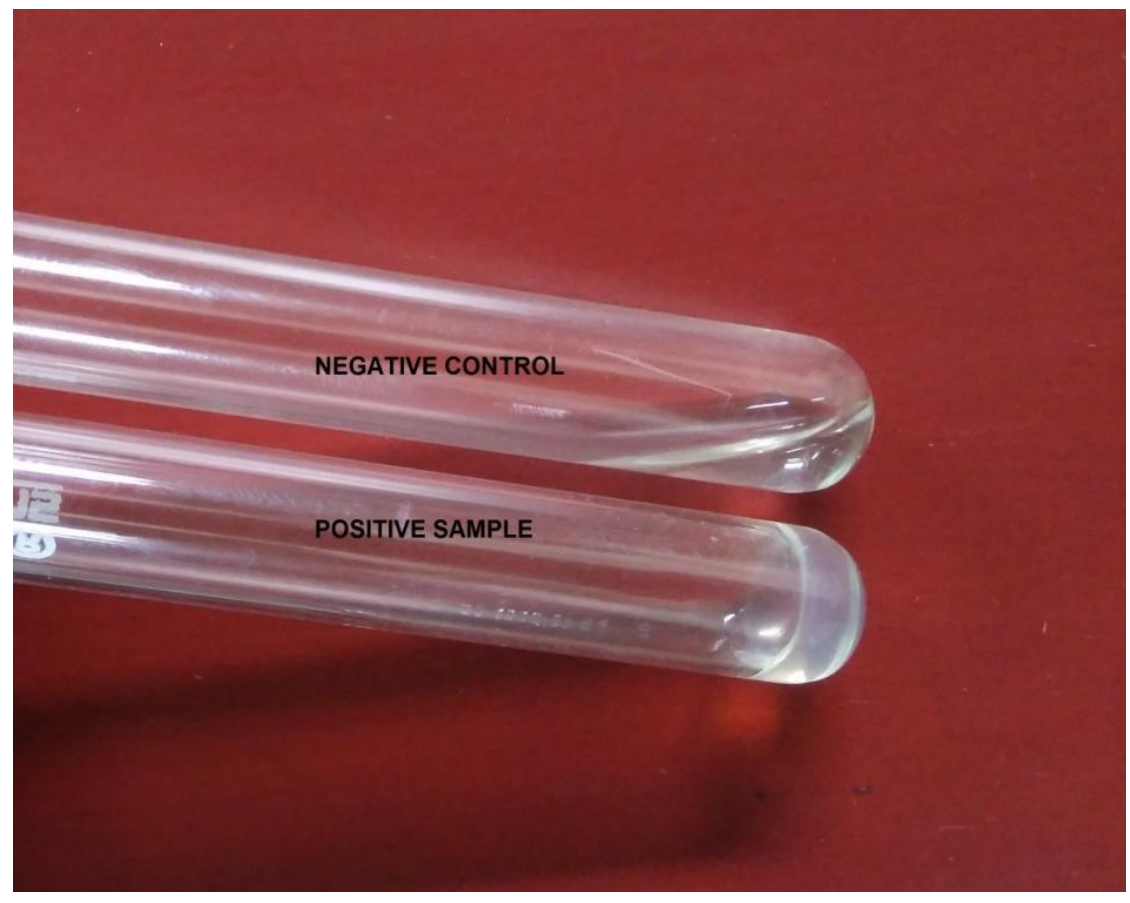


Fig.4 Partial haemolysis by $S$. aureus isolated from cattle with clinical mastitis on Sheep blood agar

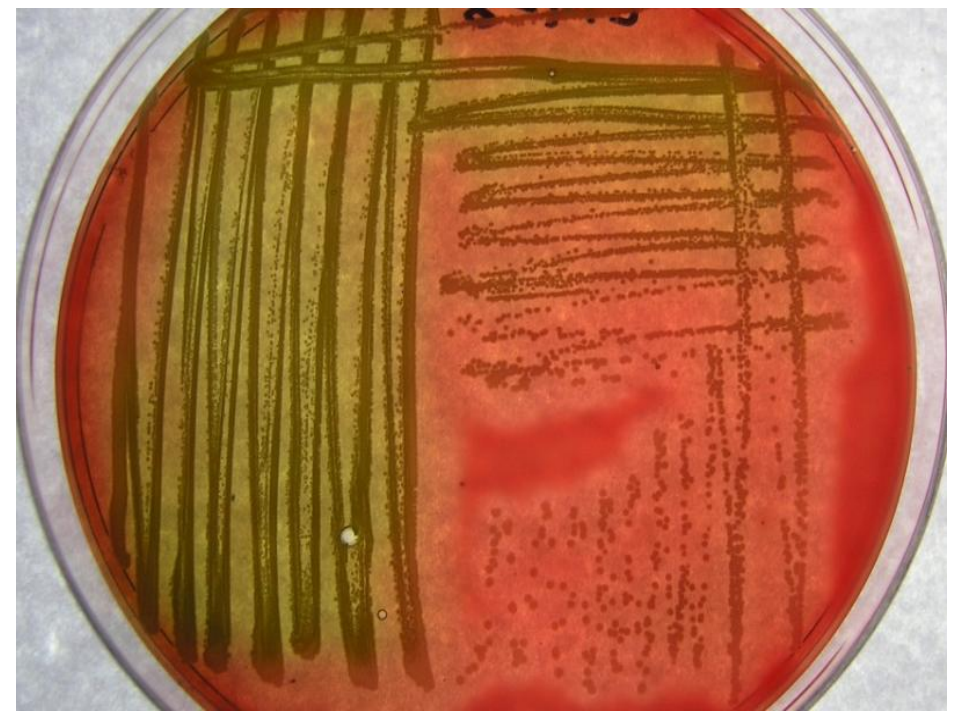

The mannitol fermentation of isolates on MSA obtained in our study is similar to earlier observations of Lange et al., (1999), Sanjiv et al., (2008), Sharma et al., (2013) and Jahan et al., (2015) who had also isolated $S$. aureus from different sources like subclinical mastitis milk, clinical mastitic milk, nasal discharge from pneumonic camels and raw cow milk, respectively. The observations made in this study is in accordance with the study of Pumipunto et al., (2017) who reported sensitivity of MSA fermentation is $100 \%$ effective in detection of S. aureus. The production of staphyloxanthina membrane bound carotenoid pigment imparts colour to the colonies in variable amounts (Clauditz et al., 2006) and protects $S$. aureus against oxidative stress. In this study only biotype 1 comprising of a single isolate and biotype 7 comprising of three isolates were recorded as yellow and white, respectively, while all other five biotypes were recorded with golden yellow pigment. Study on 143 of $S$. aureus isolates from humans and bovine raw milk samples in an Iranian province also showed that 85,38 and 20 isolates produced purple, yellow and white coloured colonies (Alini et al., 2016). El-
Jakee et al., (2010) isolated S. aureus from mastitic cows and buffalo and obtained three types of pigments viz. golden yellow, creamy and white. Quereshi and Kataria (2006) also characterized $S$. aureus from skin wounds in camel with colony pigmentation as golden yellow, yellow and white. Bhati et al., (2016) obtained $38 \mathrm{~S}$. aureus from subclinical mastitis in cattle and recorded 35 isolates with golden yellow pigmentation and three with white colonies. Hence, mannitol fermentation and pigment production can be effective tests to find variations among isolates.

In our results 27 of the 28 isolates were coagulase positive which is similar to the results reported by Kateete et al., (2010) who reported 29 out of $32 S$. aureus positive for human plasma. Sanjiv et al., (2008) also reported coagulase negative $S$. aureus isolates from clinical mastitis in cattle from the same area of study. However, other workers (Khichar and Kataria, 2015; Al-Ratha and Sekhi, 2016 and Bhati et al., 2016) did not record coagulase negative isolates from cattle mastitis. The results of haemolysis corroborated earlier reports by Yadav et al., (2015) who investigated 32 S. aureus isolates 
from milk of cattle and buffalo with clinical mastitis of which five, 20, four and three showed complete, partial, both and no haemolysis, respectively, on $5 \%$ sheep blood agar. The results in our study showed hot-cold haemolysis similar to reports of Bhati et al., (2016) who observed $33.33 \%$ of 12 isolates from subclinical mastitis in cattle to show hotcold lysis.

Phenotypic variations among Staphylococcus aureus obtained from bovine mastitis were recorded and biotyping can be an important tool to study variations among $S$. aureus.

\section{Acknowledgment}

We acknowledge the support and facilities provide Dean College of Veterinary and Animal Sciences, Bikaner, Rajasthan University of Veterinary and Animal Sciences, Bikaner for this study.

\section{References}

Alni RH, Mohammadzadeh A, Mahmoodi P (2016). Biotyping of Staphylococcus aureus strains isolated from humans and bovine raw milk samples in Hamedan province. Int $\mathbf{J}$ Health Life Sci. 2(2): 74158 .

Al-Ratha HA and Sekhi RJ (2016). The correlation between coagulase production and DNase, phosphatas, type of hemolysis produced by mastitis Staphylococcus aureus isolates and its susceptibility to some antibiotics. J. Genet. Environ. Resour. Conserv. 4(2):94-99.

Bhati T, Nathawat P, Sharma SK, Rathore P and Kataria AK (2016). Cultural biochemical and haemolytic properties of Staphylococcus aureus isolated from cases of subclinic mastitis in cattle. Int. J. Dev. Res. 06(07):8371-8375.
Clauditz A, Resch A, Wieland KP, Peschel A and Gotz, F. (2006). Staphyloxanthin plays a role in the fitness of Staphylococcus aureus and its ability to cope with oxidative stress. Infect. Immun. 74(8):4950-4953.

Cowan ST and Steel KJ (1975). Cowan and Steel's Manual for the identification of medical bacteria. Cambridge University Press, Cambridge.

Dallal MMS, Salehipour Z, Eshraghi S, Mehrabadi JF, Bakhtiari R. (2010). Occurrence and molecular characterization of Staphylococcus aureus strains isolated from meat and dairy products by PCR RFLP. Ann. Microbiol. 60(2):189-96.

Devriese LA (1984). Simplified system for biotyping Staphylococcus aureus strains isolated from different animal species. $\mathbf{J}$ Appl Bacteriol. 56(2):215-20

El-Jakee JKAH, Zaki ER and Farag RS (2010). Properties of enterotoxigenic $S$. aureus Isolated from mastitic cattle and buffaloes in Egypt. J Am Sci. 6(11):170-178.

Jahan M, Rahman M, Parvej MS, Chowdhury SMZH, Haque ME, Talukder MAK and Ahmed, S (2015). Isolation and characterization of Staphylococcus aureus from raw cow milk in Bangladesh. J Adv Vet Anim Res. 2(1):49-55.

Kateete DP, Kimani CN, Katabazi FA, Okeng A, Okee MS, Nanteza A, Joloba ML and Najjuka FC (2010). Identification of Staphylococcus aureus: DNase and mannitol salt agar improve the efficiency of the tube coagulase test. Ann Clin Microbiol Antimicrob. doi:10.1186/1476-0711-9-23.

Khichar V and Kataria AK (2015). Characterisation of Staphylococcus aureus of cattle clinical mastitis milk origin for coagulase. International 
Journal of Veterinary Science \& Research. 1(1):1-5.

Lange C, Cardoso M., Senczek D and Schwarz S (1999). Molecular subtyping of Staphylococcus aureus isolates from cases of bovine mastitis in Brazil. Vet Microbiol 67:127-141.

Momtaz H, Tajbakhsh E, Rahimi E, Momeni M (2011). Coagulase gene polymorphism of Staphylococcus aureus isolated from clinical and subclinical bovine mastitis in Isfahan and Chaharmahal va Bakhtiari provinces of Iran. Comp Clin Path. 20(5):51922.

Petrovski KR, Trajcev $\mathrm{M}$ and Buneski $\mathrm{M}$. (2006). A review of the factors affecting the costs of bovine mastitis. J S Afr Vet Assoc. 77(2):52-60.

Pumipuntu N, Kulpeanprasit S, Santajit S, Tunyong W, Kong-ngoen T, Hinthong $\mathrm{W}$ and Indrawattana N (2017). Screening method for Staphylococcus aureus identification in subclinical bovine mastitis from dairy farms. Vet. World. 10(7):721.

Quinn PJ Carter ME, Markey BK and Carter GR (1994). Clinical Veterinary Microbiology. Wolfe Publishing, Mosby-Year Book Europe Ltd. Lynton House, 7-12. Tavistock Square, London WCH 9LB, England.

Qureshi S and Kataria AK (2006). Identification of biotypes of Staphylococcus aureus isolates of camel origin. Indian Veterinary Medicine Journal.

Sanjiv K, Kataria AK, Sharma R and Singh G (2008). Epidemiological typing of
Staphylococcus aureus by DNA restriction fragment length polymorphism of coa gene. Veterinarski Arhiv. 78(1):31-38.

Seyoum B, Kefyalew H and Mukatr Y (2017). Prevalence, Associated Risk Factors and Antimicrobial Susceptibility of Staphylococcus aureus Isolated from Bovine Mastitic Milk in and Around Asella Town, Ethiopia. Adv Biol Res 11(5):295-301.

Sharma SK, Nathawat P, Bhati T, Mohammed N, Chaudhary S, Raj R, Solanki S and Kataria AK (2013). Characterization of Staphylococcus aureus isolated from nasal discharge from pneumonic camels (Camelus dromedarius). Animal Biology \& Animal Husbandry International Journal of the Bioflux Society. 5(1):38-43.

Straub JA, Hertel C and Hammes WP (1999). A $23 \mathrm{~S}$ rRNA target polymerase chain reaction based system for detection of Staphylococcus aureus in meat starter cultures and dairy products. J Food Prot. 62(10):1150-1156.

Wilson K (1987). Preparation of genomic DNA from bacteria. Curr Protoc Mol Biol. 2(4):2-4.

Yadav R, Sharma SK, Yadav J, Bhati T, and Kataria AK (2015). Phenotypic and genotypic haemolysin properties of Staphylococcus aureus obtained from milk of cattle and buffalo with clinical mastitis. Journal of pure \& applied microbiology. 9(1):349-355.

\section{How to cite this article:}

Pragya Nathiya, Kumar Gaurav, Diwakar, Sandeep Kumar Sharma and Kataria, A.K. 2018. Detection of Phenotypic Variations and Biotypes of Staphylococcus aureus Obtained from Cattle Mastitic Milk. Int.J.Curr.Microbiol.App.Sci. 7(09): 2450-2456. doi: https://doi.org/10.20546/ijcmas.2018.709.304 